\title{
Commentary: Are you too thin or too fat to have an open-chest cardiac operation? Probably not, but there are risks that you should know about
}

\author{
Victor A. Ferraris, MD, PhD
}

From the Department of Surgery, University of Kentucky, Lexington, Ky.

Disclosures: Author has nothing to disclose with regard to commercial support.

Received for publication July 27, 2019; accepted for publication July 30, 2019; available ahead of print Sept 5, 2019.

Address for reprints: Victor A. Ferraris, MD, PhD, University of Kentucky, A301 Kentucky Clinic, 740 S Limestone, Lexington, KY (E-mail: ferraris@uky.edu)

J Thorac Cardiovasc Surg 2020;160:421-2

$0022-5223 / \$ 36.00$

Copyright (c) 2019 by The American Association for Thoracic Surgery

https://doi.org/10.1016/j.jtcvs.2019.07.117

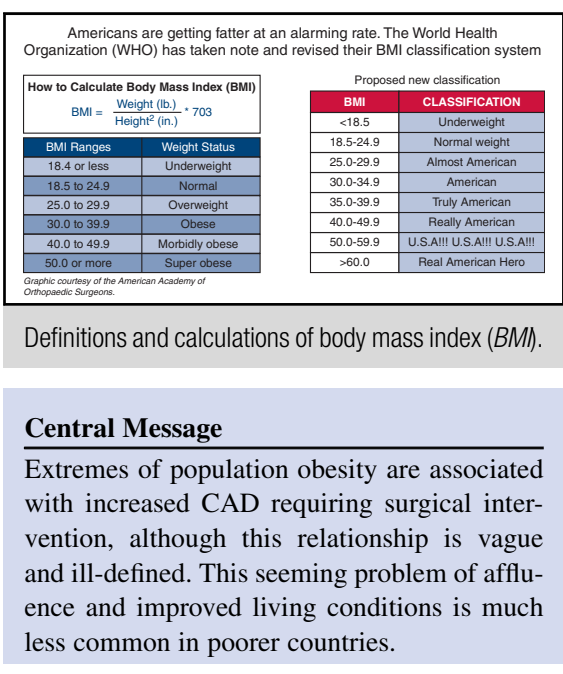

See Article page 409.
The article in this issue of the Journal by Nishioka and colleagues ${ }^{1}$ describes the use of body mass index (BMI) as a tool for optimizing coronary artery bypass grafting risks. One thing that might jump out at readers is that the level of BMI described as abnormal in a Japanese population is different from that in North American or European populations. For example, Japanese patients with BMI greater than $30 \mathrm{~kg} / \mathrm{m}^{2}$ would be considered very obese, but would be less so in European or North American populations. What is "normal" BMI differs in different populations, and this is a strong signal that a blanket statement about the relationship between BMI and cardiac surgical outcomes is not simple.

There are significant limitations to the usefulness of comparative BMI data cited by both the medical community and statisticians (https://en.wikipedia.org/wiki/List_ of_countries_by_body_mass_index\#cite_note-1). BMI data have significant weaknesses in accounting for variations in physical characteristics. It was not until the 1980s that the World Health Organization started to use BMI as a public health measure. In 1998, the National Institutes of Health adopted 6 main categories of BMI that were intended to reflect health risk: extremely obese (BMI $>40 \mathrm{~kg} / \mathrm{m}^{2}$ ), moderately obese (BMI $35-40 \mathrm{~kg} / \mathrm{m}^{2}$ ), obese (BMI 30-35 kg/m ${ }^{2}$, overweight (BMI 25-30 kg/m²), normal weight (BMI 18.5-25 $\mathrm{kg} / \mathrm{m}^{2}$ ), and underweight (BMI $<18.5 \mathrm{~kg} / \mathrm{m}^{2}$ ). ${ }^{2}$ Since that time, it has become apparent that these broad categories of BMI are simplistic and sometimes misleading. ${ }^{3}$

In this issue of the Journal, Nishioka and colleagues ${ }^{1}$ address the coronary artery bypass grafting risks associated with various BMI levels. They provide some elegant graphs to define mortality and morbidity risk in patients with high and low BMI in their results of an observational study of more than 90,000 elderly Japanese patients $(\geq 60$ years old) undergoing coronary artery bypass grafting. They assessed outcomes, including mortality and morbidity, in patients with varying BMI levels. Nishioka and colleagues ${ }^{1}$ are by no means the first group to study this relationship. Even more importantly, their results do not provide a unique observation, but rather add to some of the related studies that address the impact of BMI on cardiac surgical outcomes, and surgical outcomes in general. Table 1 lists some of the studies that have addressed the relationship between BMI and cardiac surgical outcomes. A rough consensus from recent literature suggests a correlation between BMI and surgical site infections, but this relationship is blurred both by conflicting results and by less than rigorous study designs. There does seem to be a positive correlation between adverse outcomes and extremes of BMI; however, description of a more nuanced relationship is not possible on the basis of available literature.

It is interesting to recognize the variations in population BMI. The World Health Organization conducted a study on obesity in 200 countries, collecting data based on surveys from national health ministries. According to the World Health Organization, the top 5 most obese countries are American Samoa, Nauru, Cook Islands, Tokelau, and Tonga. All these countries have an adult obesity rate greater than $60 \%$. Yes, more than half of their adult population is obese, and almost their entire adult population is overweight. For instance, American Samoa, located in the South Pacific (all top 5 nations are located in the South Pacific), 
TABLE 1. Selected surgical outcomes related to body mass index from recent literature reports

\begin{tabular}{|c|c|c|}
\hline Reference & Patient population & Outcomes related to BMI \\
\hline Zheng $^{4} 2011$ & Population study in more than 1 million Asians & $\begin{array}{l}\text { Underweight was associated with a substantially increased } \\
\text { risk of death in all Asian populations. The excess risk of } \\
\text { death associated with a high BMI, however, was seen } \\
\text { among East Asians, but not among Indians and } \\
\text { Bangladeshis. }\end{array}$ \\
\hline Protopapas $^{5} 2016$ & Literature review of 18 relevant published studies & $\begin{array}{l}\text { Patients with extreme BMIs undergoing CABG } \\
\text { (underweight patients more than morbidly obese) had } \\
\text { increased crude mortality. }\end{array}$ \\
\hline $\operatorname{Jin}^{6} 2005$ & $\begin{array}{l}\text { Observational retrospective study of } 16,218 \text { patients in } \\
\text { Northwest United States }\end{array}$ & $\begin{array}{l}\text { Body size was not a significant risk factor for CABG } \\
\text { mortality, but the lowest mortality was found in the high- } \\
\text { normal and overweight subgroups relative to obese and } \\
\text { underweight subgroups. }\end{array}$ \\
\hline $\mathrm{Liu}^{7} 2019$ & Patients with diabetes undergoing $\mathrm{CABG}$ & $\begin{array}{l}\text { BMI of the patients with diabetes undergoing CABG had } \\
\text { no effect on MACCEs. }\end{array}$ \\
\hline $\begin{array}{l}\text { Gulack }^{8} 2018 \text { and } \\
\text { Robich }^{9} 2019\end{array}$ & Secondary surgical site infections after CABG & $\begin{array}{l}\text { Surgical site infections after CABG were a source of } \\
\text { morbidity. This complication often occurred after } \\
\text { discharge and was associated with open SVG } \\
\text { harvesting, larger body mass, and blood transfusions. }\end{array}$ \\
\hline Mariscalco $^{10} 2017$ & $\begin{array}{l}\text { Effect of mild/moderate obesity on cardiac surgical } \\
\text { outcomes }\end{array}$ & $\begin{array}{l}\text { Obesity was associated with lower risks after cardiac } \\
\text { surgery, with consistent effects noted in multiple } \\
\text { analyses attempting to address residual confounding and } \\
\text { reverse causation. }\end{array}$ \\
\hline
\end{tabular}

BMI, Body mass index; $C A B G$, coronary artery bypass grafting; $M A C C E$, major adverse cardiac and cerebrovascular event; $S V G$, saphenous vein graft.

has an obesity rate of $74.6 \%$ ! According to the Organization for Economic Cooperation and Development, the countries with the most obesity are the United States $(38 \%$ of adults are obese), Mexico (32\%), New Zealand (31\%), Hungary (30\%), and Australia (28\%). There are no countries from sub-Saharan Africa that reach even the top 20 countries with significant adult obesity. There is little doubt that obesity, and attendant medical and surgical obesityrelated diseases, are a product of a higher standard of living.

\section{References}

1. Nishioka N, Ichihara N, Bando K, Motomura N, Koyama N, Miyata H, et al. Body mass index as a tool for optimizing surgical care in coronary artery bypass grafting through understanding risks of specific complications. J Thorac Cardiovasc Surg. 2020;160:409-20.e14.

2. Executive summary of the clinical guidelines on the identification, evaluation, and treatment of overweight and obesity in adults. Arch Intern Med. 1998;158:1855-67.

3. Tomiyama AJ, Hunger JM, Nguyen-Cuu J, Wells C. Misclassification of cardiometabolic health when using body mass index categories in NHANES 2005-2012. Int J Obes (Lond). 2016;40:883-6.
4. Zheng W, McLerran DF, Rolland B, Zhang X, Inoue M, Matsuo K, et al. Association between body-mass index and risk of death in more than 1 million Asians. N Engl J Med. 2011;364:719-29.

5. Protopapas AD. Does body mass index affect mortality in coronary surgery? Open Cardiovasc Med J. 2016;10:240-5.

6. Jin R, Grunkemeier GL, Furnary AP, Handy JR Jr. Is obesity a risk factor for mortality in coronary artery bypass surgery? Circulation. 2005;111: 3359-65.

7. Liu X, Zhang W, Wang L, Wang S, Yu Y, Chen S, et al. Male patients with diabetes undergoing coronary artery bypass grafting have increased major adverse cerebral and cardiovascular events. Interact Cardiovasc Thorac Surg. 2019;28: $607-12$.

8. Gulack BC, Kirkwood KA, Shi W, Smith PK, Alexander JH, Burks SG, et al. Secondary surgical-site infection after coronary artery bypass grafting: a multiinstitutional prospective cohort study. J Thorac Cardiovasc Surg. 2018;155: 1555-62.e1551.

9. Robich MP, Iribarne A, Leavitt BJ, Smith PK, Alexander JH, Burks SG, et al; Cardiothoracic Surgical Trials Network (CTSN). Intensity of glycemic control affects long-term survival after coronary artery bypass graft surgery. Ann Thorac Surg. 2019;107:477-84.

10. Mariscalco G, Wozniak MJ, Dawson AG, Serraino GF, Porter R, Nath M, et al. Body mass index and mortality among adults undergoing cardiac surgery: a nationwide study with a systematic review and meta-analysis. Circulation. 2017;135:850-63. 